\title{
A Novel Power Communication Access Network with OFDM-WDM-PON
}

\author{
Shen Wen ${ }^{1}$ Deng Hui ${ }^{1}$ Wang Wei $^{1}$ Hou Gong ${ }^{1}$ \\ ${ }^{1}$ China Electric Power Research Institute, Nan Jing, China, 210000
}

\begin{abstract}
In this paper, we propose a novel power communication access network for Orthogonal Frequency Division Multiplexing (OFDM) based WDM-PON. OFDM improved WDM-PON in the flexibility of the bandwidth allocation. The OFDM-WDM-PON can effectively seclude the distribution services from the electricity services. Furthermore the novel PON structure could increase the bandwidth by using different OFDM subcarrier allocation used in electric power communication access network.
\end{abstract}

Keywords: PON, WDM, OFDM, Power Communication Access Network

\section{Introduction}

The access network is an important part of the power communication network, which is the overall carrying platform that access communication services in distribution and electricity sectors [1].

Passive optical network (PON) technology has become the most attractive solution in access networks because of its topology diversity, high-rate, applicable to IP services, the mature terminal equipment and the lower the cost of network construction [2]. According to the "12th Five-Year Plan", optical fiber will be given priority to the architecture of electricity smart grid communications network [3]. In our state smart grid, the research and development of PON system had been carried out in the field of This paper is sponsored by the National 863 Plan Project Funds (2011AA05A116) China, 2011.

(C) 2013. The authors - Published by Atlantis Press communication assessment, control and management to provide advanced technical support, in order to develop intelligent electricity distribution [4].

However, with the deepening of the smart grid construction, the traditional PON technology cannot meet the future development requirement of the power communication access network as a variety of complex services continuously raised [5]:

(1) Business seclusion. Power communication network's distribution should be secluded from the electricity service.

(2) Bandwidth provision. The current bandwidth is not wide enough to meet the requirement of the rapid growth of business in power communication access network. Existing passive optical network bandwidth will be unable to meet the communication needs.

(WDM-TDM) PON, a hybrid wavelength division multiplexing-time division multiplexing PON has been considered as a potential solution for the power communication access network [6, 7]. Because of the bandwidth sharing of the TDM-PON, the WDM-TDM PON could provide a relatively lower per-subscriber cost than the pure WDM-PON by dividing a single wavelength into multiple subscribers, while still keeping a relatively high per-subscriber bandwidth.

OFDM is a kind of has been applied in the field of wireless multi-carrier modulation technique [8, 9]. It has high spectrum efficiency, resistance to multipath fading and narrowband interference. The OFDM 
modulation technique can be applied to WDM-PON, and constitute the OFDMWDM-PON [10]. This kind of method can realize parallel transmission of the large capacity information, while support flexible business scheduling and minimize granularity in dynamic bandwidth allocation.

In this paper we applied WDM-PON with OFDM to the power communication networks, in order to support the reuse of various terminal architecture of information transmission and realize a minimized dynamic bandwidth allocation.

\section{Related Work}

\subsection{WDM-PON}

WDM-PON is based on wavelength division multiplexing (WDM). This kind of PON achieved one point to multi-point communication, which uses the wavelength as identification for each ONU. WDM-PON achieved multiple access, while make full use of optical fiber transmission bandwidth.

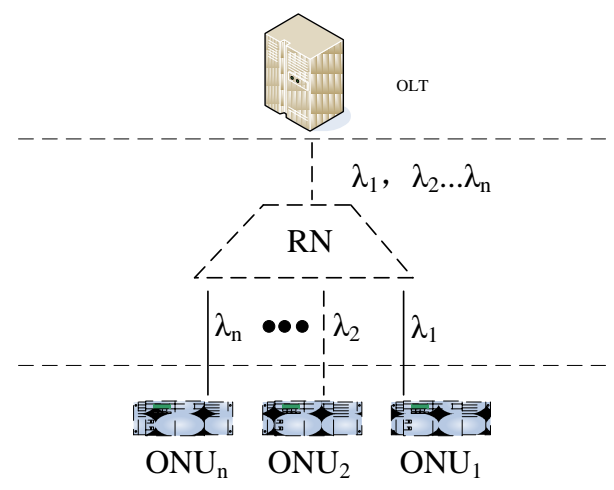

Fig. 1: WDM-PON Architecture

\subsection{OFDM}

OFDM modulates baseband signals in the signal transmitter. The signals are conversed in frequency in the MZM, and transmitted to outer modulation, turned into light signals (optical OFDM signals). Then OFDM signals are sent through the transmitters in optical fiber to the receiver part. Direct detection receiver using photoelectric detector can receive these optical signals. After OFDM signals are converted into electricity ones. They will be conversed in frequency for OFDM baseband signal demodulation. OFDM signal transmitter and the receiver structure is shown in figure 2 .

In the transmitter part, signals are converted from string to parallel. Subcarrier symbol map these signals, and use the IFFT transformation to realize the modulation of OFDM. A protection interval and D/A transform form baseband signals are added.

In the receiver, protection intervals in received signals are removed after $\mathrm{A} / \mathrm{D}$ transformation. Fir transformation is used to realize the demodulation of OFDM. OFDM modulation of optical signal with high frequency spectrum utilization, antimultipath interference capability is strong, excellent tolerance to the degree of dispersion and polarization mode dispersion, etc. OFDM can be easily combined with a variety of multiple access techniques. Provide access to multiple users at the same time. Therefore it can be combined with WDM - PON named OFDM-WDM-PON.

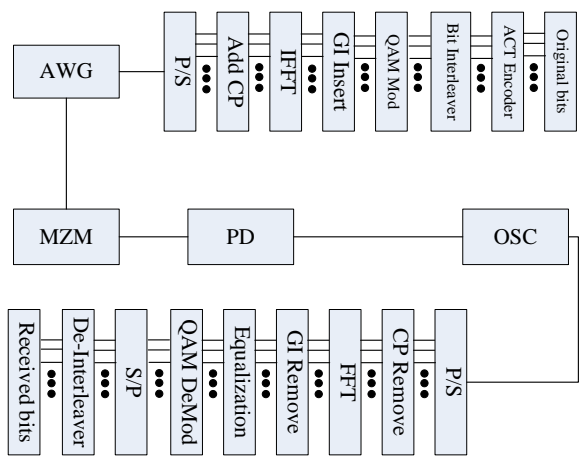

Fig. 2: OFDM Transmit and Receive Process 
OFDM modulation technology can adjust to the dynamic distribution subcarrier channel conditions for the ONUs in the users' part. OFDM process can fill the WDM - PON the poor business scheduling flexibility.

\section{OFDM-WDM-PON in Power Communication Access Networks}

OFDM signals use the single mode optical fiber in the two polarizations to/downlink information transmission because of the polarization mode dispersion characteristics. In this paper, we put forward the OFDM-based WDM-PON on polarization multiplexing. As shown in figure 3 .

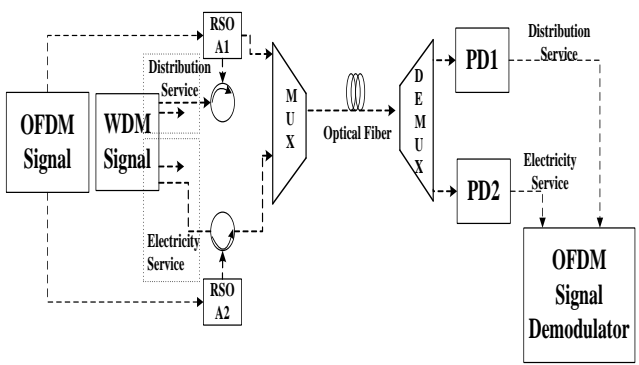

Fig. 3: OFDM-WDM signal transmission process.

First of all, laser LD produces optical carrier, then the carrier is separated into two polarizations by polarization beam splitter (PBS). After that intensity modulation (IM) is applied in the polarization controller (PC) X polarization. Then the light OFDM signal is carried on the $\mathrm{X}$ polarization. At the same time, the module process still keeps the polarization state of the $\mathrm{Y}$ to carry the uplink information. Polarization of $\mathrm{Y}$ and the modulated Polarization of $\mathrm{X}$ are combined in polarization beam splitter (PBC). Finally the combined signals are transmitted through a wavelength division multiplexer by single mode fiber (SMF) to
ONUs. Optical signals then are demodulated after wavelet multiplex solutions for reuse and assigned to each ONU. In each ONU, the optical signals are separated into two polarization state by PBS. The modulated information of polarization $\mathrm{X}$ is demodulated directly. The un-modulated polarization of $\mathrm{Y}$ is sent to the modulator to generate optical signals for uplink information. Using to transmit data ONU uplink OFDM modulation, OFDM signal light upward, returned to the OLT. Finally obtained uplink signals in the loop device receives are sent to the receiver array detection, in order to realize the use of optical signals on the same optical fiber polarization of $\mathrm{X}$, Y, two-way transmission of information. WDM - PON OFDM - take full advantage of the characteristics of the OFDM modulation.
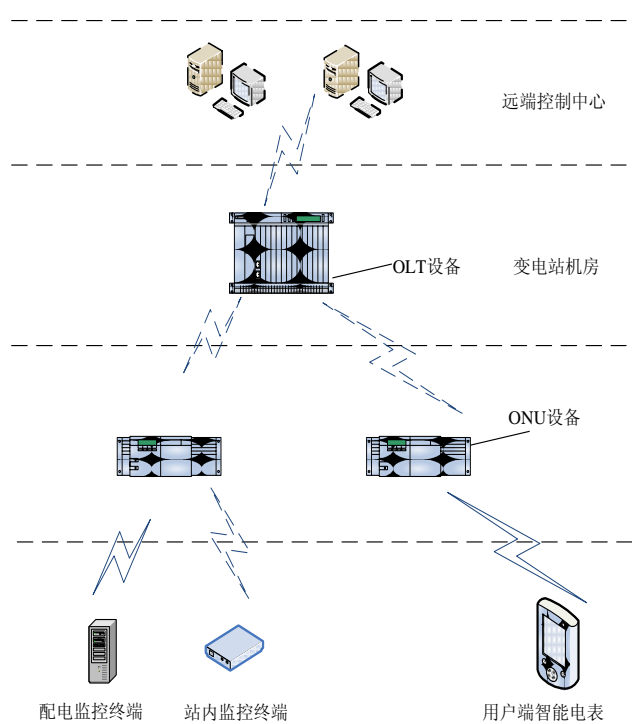

Fig. 4: The Architecture of Power Communication Access networks.

Combined with polarization multiplexing technology, this paper presents an OFDMWDM-PON implementation method. This method improved WDM-PON in the 
flexibility of the bandwidth allocation. The OFDM-WDM-PON can effectively seclude the distribution services from the electricity services. Furthermore the novel PON structure could increase the bandwidth by using different ONU OFDM sub-carrier allocation used in electric power communication access network.

\section{Conclusion}

In this paper, we apply optical OFDM signals to the WDM-PON in power communication access networks. The characteristics of high flexibility of the bandwidth allocation design makes OFDM-WDM-PON an efficient method to seclude the distribution services from the electricity services. In this method, the PON structure is enhanced, and raised the ability to the electric power communication access network capacity.

\section{References}

[1] Y. Zhang, L. Chen, Z. Cao, "Experimental research about a fullduplex OFDM-ROF system based on intensity modulation," Chinese Lasers, pp. 1744-1749, 2010, 37(7).

[2] L. Chen, Z. Huang, "Application of transmission line condition monitoring technology based on Internet of Things in smart grid," Modern Electronics Technique, pp. 7-9, 2012, 35(21).

[3] Y. Li, Y. Fang, Y. Shao, N. Chi, "Research on PoN based on several OFDM multiplexing modes," Study on optical communications, pp. 7-10, 2012, 2.

[4] G. Chang, A. Chowdhury, J. Zhen, C. Hung, M. Huang, J. Yu, G. Ellinas, "Key Technologies of WDM-PON for Future Converged Optical Broadband Access Networks," IEEE/OSA Journal of Optical Communications and Networking, pp. C35-C50, 2009, 1(4).
[5] V. Bobrovs, S. Spolitis, G. Ivanovs, P. Gavars, "Performance improvement of high speed spectrum-sliced dense WDM-PON system," 2012 IX International Symposium on Telecommunications (BIHTEL), pp. 16, 2012.

[6] J. Kani, "Enabling Technologies for Future Scalable and Flexible WDMPON and WDM/TDM-PON Systems," IEEE Journal of Selected Topics in Quantum Electronics, pp. 1290-1297, 2010, 16(5).

[7] Y. Hsueh, M. Huang, S. Fan, G. Chang, "A Novel Lightwave Centralized Bidirectional Hybrid Access Network: Seamless Integration of RoF With WDM-OFDM-PON," IEEE Photonics Technology Letters, pp. 1085-1087, 2011, 23(15).

[8] E. Giacoumidis, J. L. Wei, X. L. Yang, A. Tsokanos, J. M. Tang, "AdaptiveModulation-Enabled WDM Impairment Reduction in Multichannel Optical OFDM Transmission Systems for Next-Generation PONs," IEEE Photonics Journal, pp. 130-140, 2010, 2(2).

[9] E. Wong, "Next-Generation Broadband Access Networks and Technologies," Journal of Lightwave Technology, pp. 597-608, 2012, 30(4).

[10]Y. Lin, P. Tien, "Next-generation OFDMA-based passive optical network architecture supporting radioover-fiber," IEEE Journal on Selected Areas in Communications, pp. 791-799, 2010, 28(6). 